\title{
THE CORONARY CIRCULATION IN COMPLETE TRANSPOSITION OF THE GREAT VESSELS
}

\author{
BY \\ REDA M. SHAHER \\ From the Cardiac Department, Guy's Hospital, London
}

Received September 19, 1962

While the anatomy of the coronary arteries in complete transposition of the great vessels has been studied by several authors, the overall problem of adequacy of the coronary blood supply in this condition has received less attention. Spitzer (1923) described the probable embryological basis for partial or complete transposition of the coronary arteries. Astley and Parsons (1952) thought that myocardial ischæmia was an important factor in causing cardiac-enlargement in cases of complete transposition of the great vessels. Keith et al. (1953) dissected the coronary arteries in 37 cases of complete transposition, and in 1958 reviewed their anatomy in 80 cases, differentiating them into four main patterns.

With the development of techniques for the correction of complete transposition of the great vessels such considerations are of considerable importance. Apart from the anatomical abnormalities that may occur, e.g. a single coronary artery, an ischæmic myocardium may be partly responsible for the high mortality from any form of surgical procedure in cases of complete transposition.

The object of this paper is to report the cases of complete transposition of the great vessels seen in Guy's Hospital in whom any abnormal feature of the coronary arteries, the myocardium, or the endocardium was found at autopsy. Other reports about this are reviewed, and the probable explanation of myocardial ischæmia in cases of complete transposition is discussed.

\section{SubjeCtS AND MeThod}

Seven cases of complete transposition of the great vessels were seen at Guy's Hospital, in each of which the anatomical diagnosis was confirmed at autopsy. Their ages ranged from 2 weeks to 29 years. There were 3 male and 4 female subjects. One case had closed atrial and ventricular septa and no associated defects (the method of survival in this case was not apparent at autopsy), and the remaining six had a large ventricular septal defect as the major associated defect. Dissection of the coronary arteries was carried out by the author in Cases 1, 2, and 7, whose hearts were available at the time of writing this paper. In the remaining cases details of the coronary arterial anatomy were obtained from the post-mortem reports. A study of the coronary circulation by means of selective right ventricular angiography was also done in Case 2. Sections from the myocardium were obtained from all cases except Case 3, but from the right ventricle only from Case 5. Sections were stained with hæmalum and eosin stain and Weigerts' elastic stain, iron hæmatoxylin, and van Gieson stain.

\section{Anomalies of the Coronary Arteries \\ (a) Absent Left Circumflex Artery}

Case 1. The man died at the age of 24 years in a road accident. At autopsy complete transposition of the great vessels was confirmed. A large ventricular septal defect and great dilatation of the pulmonary 
artery were demonstrated. The right coronary artery, which was much the larger of the two, arose from the posterior aortic sinus. Immediately after its origin it became very irregular and tortuous and broke up into a plexus of radiating branches on the lateral wall of the right ventricle. The left coronary artery was a much smaller vessel and arose from the left anterior sinus. It descended vertically in the anterior interventricular groove and divided after about $3 \mathrm{~cm}$. into two small branches that supplied the interventricular septum and the muscle of the anterior wall of the left ventricle. Its circumflex branch was absent. Sections from the left ventricle showed no fibrosis, while sections from the right ventricle showed a few foci of fibrosis largely in columni carneæ.

Case 2. A girl aged 4 years died after an operation to correct complete transposition of the great vessels. Angiography with injection of the dye into the right ventricle had demonstrated dilatation and tortuosity of the coronary arteries, the left circumflex artery being absent (Fig. 1). At operation there was a ventricular septal defect, $1 \times 0.75 \mathrm{~cm}$., and the pulmonary arterial pressure was equal to the aortic pressure. At autopsy, the left coronary artery arose from the left anterior sinus and descended over the anterior wall of the left ventricle, its left circumflex branch being absent. The right coronary artery arose $0.5 \mathrm{~cm}$. above the posterior sinus and divided into two branches that supplied the right ventricle. Sections taken from the left ventricle showed moderate hypertrophy of muscle fibres and no fibrosis, whereas sections taken from the right ventricle showed greater hypertrophy and very mild fibrosis patchily distributed.

\section{(b) Dilatation of the Coronary Arteries}

Case 3. A woman died at the age of 29 years following an operation to relieve her pulmonary stenosis. At operation the condition of complete transposition of the great vessels was discovered. The anterior descending coronary artery demarcating the two ventricles was about $1 \mathrm{~cm}$. in diameter (Fig. 2). There 


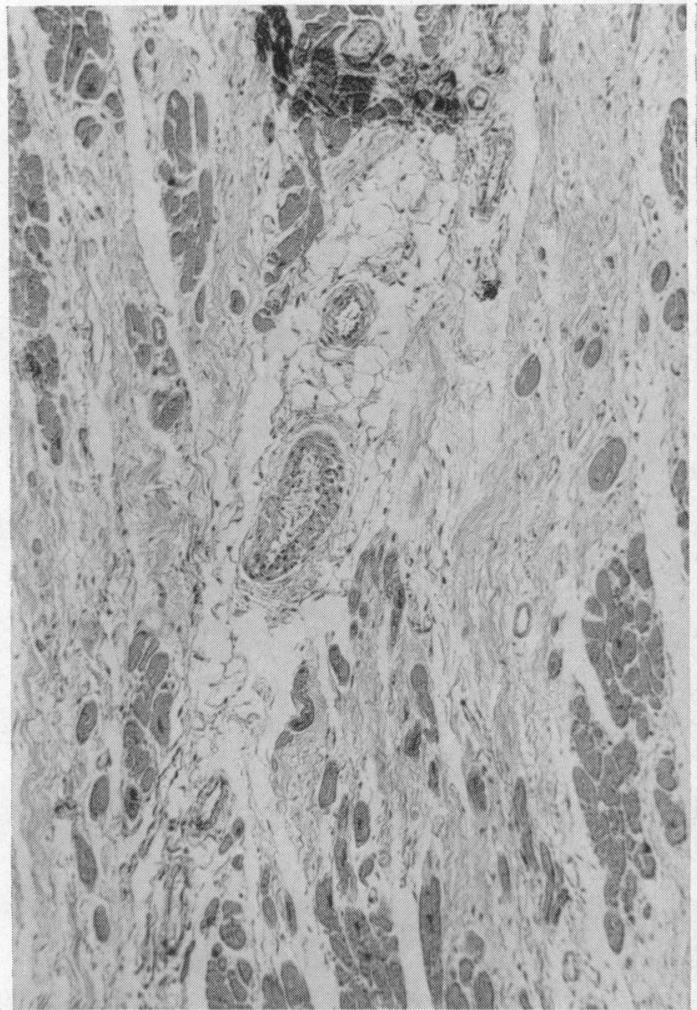

FIG. 3.-Case 4. Section from right ventricle, showing diffuse myocardial fibrosis. $(\times 100$. $)$

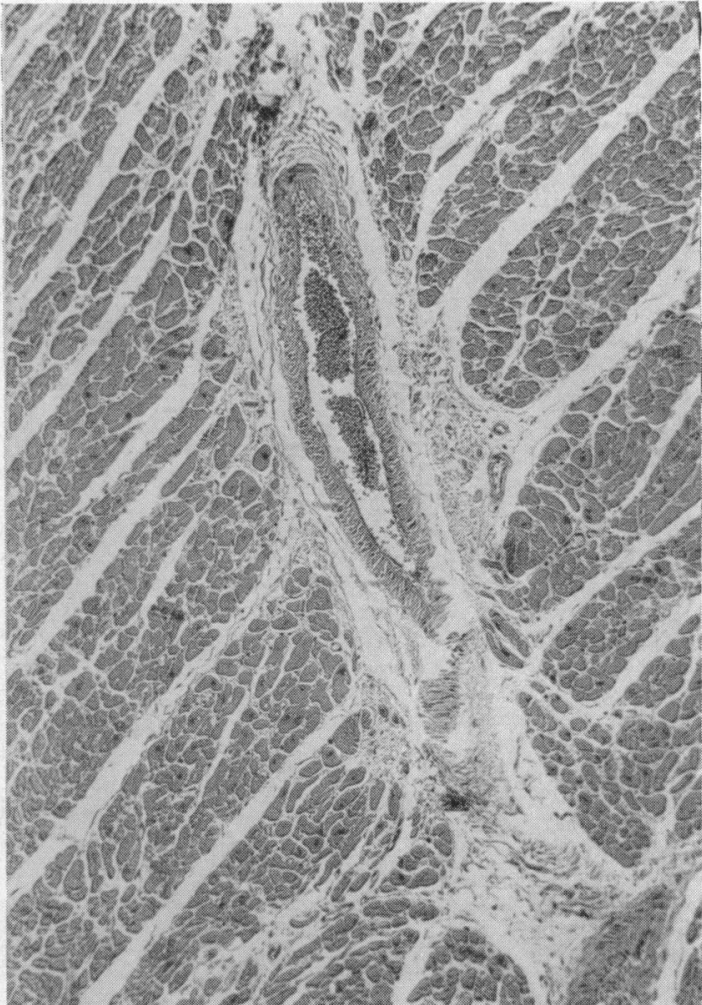

FIG. 4.-Case 4. Section from left ventricle, showing perivascular fibrosis. $(\times 100$.

was both pulmonary valvar and infundibular stenosis, the valve being calcified. Both ventricles were much hypertrophied. Autopsy confirmed these findings and showed that the coronary arteries were very dilated and tortuous.

Dilatation of the coronary arteries was also found in Cases 1, 2, 4, and 5.

\section{MYOCARDial AND ENDOCARDIAL Fibrosis}

Case 4. A woman died at the age of 25 years following thoracotomy. At autopsy, complete transposition of the great vessels was found to be present. There was a small atrial septal defect, $5 \times 2 \mathrm{~mm}$. in diameter, and a large ventricular septal defect situated in the upper part of the septum. There was pulmonary infundibular stenosis, and the pulmonary valve cusps showed partial fusion of two of them. The right coronary artery was normal. The left sprang by a large mouth from the left anterior sinus. Its short trunk was the size of a normal carotid. Soon after it divided into a normal left coronary artery and an aberrant branch which ran downwards over the right ventricle. Sections from the right ventricle showed hypertrophy of muscle fibres and replacement fibrosis in large amounts. The whole myocardium was diffusely affected, but at the same time there was no lack of blood vessels, capillaries, nor any thrombosis of the vessels (Fig. 3). The left ventricular muscle showed no hypertrophy but there were occasional clearly defined patches of focal replacement fibrosis in the muscle, unrelated anatomically to any particular site, but often occurring in the neighbourhood of blood vessels (Fig. 4).

Case 5. A woman died at the age of 24 years as a result of hæmorrhage into the gastro-intestinal tract. At autopsy transposition of the great vessels was confirmed. The pulmonary valve was $1 \mathrm{~mm}$. in diameter and was calcified. The aortic ring was dilated and the cusps did not meet. There was a ventricular septal defect measuring $2 \mathrm{~cm}$. in diameter. There were numerous subendocardial fibrotic plaques some reaching the 
deeper myocardium. Numerous collateral vessels were present in the pericardial reflections and lung roots. The coronary arteries were very wide and tortuous, measuring $1 \mathrm{~cm}$. in external diameter, and they appeared as circoid aneurysms throughout the heart surface. Sections from the right ventricle showed severe myocardial hypertrophy. There was patchy myocardial fibrosis, considerable in parts (Fig. 5).

Case 6. A boy died at the age of 2 weeks. At autopsy the great vessels were transposed, there was some dilatation of the right atrium and ventricle. The foramen ovale was closed and there were no septal defects. At the bifurcation of the pulmonary artery a blind ductus arteriosus was found. Sections from the myocardium showed focal replacement fibrosis.

Case 7. A boy died at the age of 3 months, a few hours after an operation for correction of complete transposition of the great vessels. At operation a ventricular septal defect measuring $1.5 \mathrm{~cm}$. was found. There was no pulmonary stenosis. At autopsy the left coronary artery was found arising from the left anterior sinus and divided into a left circumflex and anterior descending branches. The right coronary artery arose from the posterior sinus and gave a right marginal and posterior descending branches. Sections from the left ventricle showed slight hypertrophy and no fibrosis. Sections from the right ventricle showed only an occasional tiny focus of fibrosis, except in one subendocardial area. Here there was severe fibrosis which had replaced muscle and was separated from the endocardium by a thin layer of fibrin (Fig. 6). Endocardial fibrosis was also present in Case 5.

\section{Discussion}

Anatomy. The most satisfactory classification of the anatomy of the coronary arteries in complete transposition of the great vessels is that suggested by Keith, Rowe, and Vlad (1958).

(1) Course of the vessels essentially normal. This occurred in 7 per cent of their 80 cases. The left coronary artery arises from the posterior aortic sinus and passes behind and to the left of the 
pulmonary artery: it branches off into an anterior descending branch and a left circumflex artery. The right coronary artery arises from an anterior aortic sinus usually the left, courses to the right, and gives off a right marginal branch and a terminal posterior descending branch.

(2) Transposition of the coronary arteries. This is the most common type and occurred in $52(67 \%)$ of their cases. The left coronary artery arises from behind the left anterior aortic sinus, in the position usually occupied by the right coronary artery: the left circumflex and the anterior descending branches have a normal course and distribution. The right coronary artery arises from the posterior sinus. Its main trunk lies behind the posterior surface of the aorta. It gives off the right marginal and posterior descending branches.

(3) Left circumflex arising from the right coronary artery. This occurred in $19(23 \%)$ of their cases. The coronary arteries are transposed, but the left circumflex branch appears as the first branch of the right (posterior) coronary artery: it winds around the pulmonary artery and ends in the lateral wall of the left ventricle. The left coronary artery is represented by the sole descending branch.

(4) All branches from a single orifice. All branches of the right and left coronary arteries arise from a single orifice situated behind either the left anterior aortic cusp or the posterior cusp. This occurred in 2.5 per cent of their cases.

There are, however, reported cases that cannot be fitted into any of these four groups. Case 8 of Harris and Farber (1939) had three anterior descending coronary arteries. The extreme left one arose from the posterior sinus and gave rise to the left circumflex artery. The middle and right anterior descending arteries arose by two separate orifices from the left anterior sinus, the right giving rise to the right circumflex and the posterior descending arteries. Case 12 of Harris and Farber had a single artery arising from the posterior aortic sinus: it divided into several branches supplying the heart, but none of them resembled the arteries of a normal coronary circulation. Two of our cases did not have a left circumflex branch at all. In Case 1, the right coronary artery broke up into a plexus of radiating branches on the lateral wall of the right ventricle, while the left coronary divided into two small anterior descending arteries. In Case 4, the left coronary artery sprang by a large mouth from the left anterior sinus and divided into a normal left and an aberrant branch that ran downwards over the right ventricle.

Transposition of the coronary arteries, as defined by Spitzer (1923), strictly means exchange of the orifices of the two coronary arteries from their respective aortic sinuses. As detorsion of the aorta takes place and the aorta winds around the pulmonary artery in an anti-clockwise direction, rotation of the coronary-bearing sinuses occurs. The right anterior sinus, which normally gives origin to the right coronary artery, comes to lie in the left anterior position and gives rise to the left coronary artery. The left anterior sinus, which normally gives rise to the left coronary artery, comes to lie posteriorly and gives rise to the right coronary artery. Spitzer explained the anomalies of the coronary arteries in transposition of the great vessels by the anti-clockwise rotation of the sinus and the stem of one coronary artery to the region of the other. In this way the blood-stream direction in the stem of this coronary artery is brought into the course of the branches of the other. In other words anastomosis occurs between the stem of one coronary artery and branches of the second vessel. When one branch of a coronary artery is transposed to the stem of the other coronary artery, while the second branch remains attached to the parent aortic sinus, partial transposition of the coronary arteries is said to be present. Group 3 of Keith et al. (1958) belongs to this category, because the left circumflex artery is still attached to the parent left anterior sinus which is now lying in the posterior position, while the anterior descending artery is arising from the right anterior sinus which is now lying in the left anterior position.

It is necessary, if Spitzer's explanation is true, that the coronary arteries must develop before or during the division of the truncus arteriosus into the aorta and the pulmonary trunk. Grant (1926) described the development of the coronary system in rabbits: the coronary veins are the first to appear and are seen as outgrowths of the endothelium lining the left horn of the sinus venosus in embryos of about $7 \mathrm{~mm}$. total length; and the coronary arteries appear a little later, the left rather 
before the right, in embryos of 10-11 mm. length, as endothelial sprouts from the base of the aorta before the truncus had been divided by the spiral septum into aorta and pulmonary trunk. Patten (1960) thought that the human coronary arteries arose during the seventh week of fotal life from the aorta shortly after it had been partitioned off by the division of the truncus arteriosus. Since Spitzer explained transposition of the coronary arteries on the basis of simultaneous rotation of the aorta and the developing coronary arteries, his theory is untenable if the coronary arteries develop after the division of the truncus arteriosus by the spiral septum. Spitzer's theory will not explain those cases in which the origin and course of the vessels are normal or there is a single coronary artery.

Reemtsma, Longenecker, and Creech (1961) studied the distribution of the major coronary arteries in 154 congenitally malformed hearts and 24 normal hearts. They concluded that abnormalities of the coronary arteries, such as origin of the anterior descending coronary artery from the right coronary artery or a single coronary artery with the left coronary branch passing across the right ventricle, most frequently occur in transposition complexes and in Fallot's tetralogy with extreme dextroposition of the aorta.

The Myocardium and Endocardium. An interesting feature observed in our Cases 2, 4, 5, and 6 is the occurrence of variable degrees of patchy or diffuse myocardial fibrosis which had affected the two ventricles differently in Cases 2 and 4. Astley and Parsons (1952) thought that microscopic examination of the myocardium in transposition always showed necrobiotic changes in the heart muscle with loss of striations, nuclear degeneration, hyaline changes, and destruction of muscle fibres, which is often severe. Campbell and Hudson (1958) described the coronary circulation in a patient with Taussig-Bing transposition who lived for 34 years. The coronary arteries showed minimal atheroma and no occlusion for as far as they could be opened. In the myocardium of both ventricles there were numerous small scattered areas of necrosis that were probably ischæmic, and there were one or two similar but smaller lesions in the right atrium. A striking feature of most sections was the deposition of calcium in the necrotic areas and also in the intima and media of arteries. Bernreiter (1958) reported a case of a 7-week-old baby with transposition of the great vessels, closed ventricular septum, patent foramen ovale, and patent ductus arteriosus. Before death the electrocardiogram showed the pattern of myocardial infarction and at autopsy small areas of ischæmic necrosis associated with interstitial hæmorrhages in the septum were found. Five of the 18 patients reported by Noonan et al. (1960) complained of chest pain: in the one who died, moderate coronary arteriosclerosis was found post mortem. The cardiogram of one of a group who cried as though they were in pain showed signs of myocardial ischæmia, and histological evidence of subacute myocardial necrosis was found at autopsy. An additional infant also was found to have myocardial necrosis. Two other infants not included in their report, whose hearts were examined by the Pathological Department at The Children's Centre, showed focal areas of myocardial infarction.

For life to continue in complete transposition of the great vessels, an equal bidirectional shunt has to occur between the two circuits. There is strong evidence that the shunt in complete transposition is limited and does not usually exceed $1-31 . / \mathrm{min} . / \mathrm{m} .{ }^{2}$ (Shaher, 1963a). It has been shown that for the occurrence of the bidirectional shunt, a hyperkinetic circulation develops in the systemic or pulmonary circulation depending on the presence or absence of severe pulmonary stenosis or a high pulmonary vascular resistance (Shaher, 1963a). This unique hæmodynamic situation is complicated by the ventricles being perfused with grossly desaturated coronary arterial blood. The ventricles respond to this increased amount of work by hypertrophy and dilatation. Increased coronary flow, and dilatation and tortuosity of the coronary arteries occur, as in our Cases 1, 2, 3, 4, and 5. Since the nutritional needs of each muscle fibre depend on its cubic volume, whereas its nutritional supply is proportional to its surface area, disparity between demand and supply may ultimately result. This disparity is aggravated as the coronary arterial blood becomes increasingly desaturated. When the disparity increases gradually, the muscle fibres may atrophy and progressive replacement fibrosis may occur. Calcification of some muscle fibres and 
compensatory hypertrophy of others may also occur as in Campbell's case. When the disparity between the myocardial demand for blood and the coronary blood supply is acute, myocardial infarction may result.

It is known that at birth in complete transposition the heart is close to normal size and shape but after three to four weeks it becomes considerably enlarged to both right and left (Brown, 1950; Astley and Parsons, 1952; and Keith et al., 1953). Astley and Parsons (1952) thought that myocardial ischæmia was the important factor responsible for this cardiac enlargement. It is hard to accept this concept, for ischæmia that was responsible for this degree of cardiac enlargement would hardly allow a person to live 10-20 years. Moreover myocardial fibrosis does not occur in all cases of complete transposition, and even when it does, it is usually minimal in babies a few weeks old. It is conceivable, however, that the rapid cardiac enlargement in the neonatal period may precipitate an acute discrepancy between the myocardial demand for blood and the coronary blood supply, resulting in myocardial infarction. This may explain the curious occurrence of myocardial infarction in babies with complete transposition of the great vessels (Bernreiter, 1958; and Noonan et al., 1960). It appears that babies with a closed ventricular septum are more liable to develop this complication in view of their lower degree of arterial $\mathrm{O}_{2}$ saturation (Noonan et al., 1960; and Shaher, 1963b). Brown (1950) thought that the rapid cardiac enlargement in complete transposition was a result of shunts through persistent orifices, but since the bidirectional shunt in complete transposition of the great vessels is limited, it seems that the rapid cardiac enlargement is related to the establishment, soon after birth, of a hyperkinetic circulation in the pulmonary or systemic circulation, which is not a function of the degree of shunting (Shaher, 1963a).

Endocardial fibro-elastosis may occur in complete transposition of the great vessels. It occurred in our Cases 5 and 7. The case described by Pung, Gottstein, and Hirsch (1955) showed that the lining of the right atrium, atrial appendage, and the right ventricle was slightly thickened by fibrous tissue. The endocardial lining of the left atrium, atrial appendage, and left ventricle was similarly affected. Endocardial fibro-elastosis occurred in 6 of the 21 autopsy findings, described by Noonan et al. (1960), and in one of the cases of Keith et al. (1958). Whether this endocardial fibrosis is another manifestation of the precarious coronary circulation in complete transposition or the result of dilatation and stretch of the myocardium has been discussed by Still (1961).

\section{SUMMARY}

Seven cases of complete transposition of the great vessels were seen at Guy's Hospital, in each of which the anatomical diagnosis was confirmed by autopsy. Absent left circumflex artery was found in 2, dilatation of the coronary arteries in 4 , myocardial fibrosis, mainly affecting the right ventricle in 4, and endocardial fibro-elastosis in 2 cases.

The embryology and anatomy of the coronary arteries in complete transposition of the great vessels is discussed. The ætiology of myocardial ischæmia in this condition is thought to be due to discrepancy between the myocardial demand for blood and the coronary blood supply. When this discrepancy is acute, myocardial infarction may occur; and when it is gradual, progressive myocardial fibrosis may develop.

I am indebted to Drs. C. G. Baker, D. C. Deuchar, and D. H. Davies for helpful criticism, to Drs. C. G. Baker, D. C. Deuchar, P. R. Mac Keith, and Mr. D. N. Ross for permission to study their cases. I am grateful to Dr. G. A. K. Missen for his reports on the slides and to Mr. P. Molloy for his help with the dissection of the coronary arteries. I wish to thank Miss D. Healy for her assistance during the preparation of this paper. 


\section{REFERENCES}

Astley, R., and Parsons, C. (1952). Complete transposition of the great vessels. Brit. Heart J., 14, 13.

Bernreiter, M. (1958). Myocardial infarction in an infant with complete transposition of the great vessels. J. Amer. med. Ass., 167, 459.

Brown, J. W. (1950). Congenital Heart Disease, 2nd ed. Staples, London.

Campbell, M., and Hudson, R. E. B. (1958). A case of Taussig-Bing transposition with survival for 34 years. Guy's Hosp. Rep., 107, 14.

Grant, R. T. (1926). Development of the cardiac coronary vessels in the rabbit. Heart, 13, 261.

Harris, J. S., and Farber, S. (1939). Transposition of the great cardiac vessels with special reference to the phylogenetic theory of Spitzer. Arch. Path., 28, 427.

Keith, J. D., Neill, C. A., Vlad, P., Rowe, R. D., and Chute, A. L. (1953). Transposition of the great vessels. Circulation, 7, 830.

一, Rowe, R. D., and Vlad, P. (1958). Heart Disease in Infancy and Childhood. Macmillan, New York.

Noonan, J. A., Nadas, A. S., Rudolph, A. M., and Harris, G. B. C. (1960). Transposition of the great arteries: a correlation of clinical, physiologic, and autopsy data. New Engl. J. Med., 263, 592.

Patten, M. P. (1960). In Pathology of the Heart, 2nd ed, ed. S. E. Gould. Thomas, Springfield, Illinois.

Pung, S., Gottstein, W. K., and Hirsch, E. F. (1955). Complete transposition of the great vessels in a male aged 18 years. Amer. J. Med., 18, 155.

Reemtsma, K., Longenecker, C. G., and Creech, O., Jr. (1961). Surgical anatomy of the coronary artery distribution in congenital heart disease. Circulation, 24, 782.

Shaher, R. M. (1963a). The prognosis of complete transposition of the great vessels with and without an atrial septal defect. Brit. Heart J., 25, 211.

(1963b). The hæmodynamics of complete transposition of the great vessels. In preparation for publication.

Spitzer, A. (1923). Uber den Bauplan normalen und missbildeten Herzens (Versuch einer phylogenetischen Theorie). Virchows Arch. path. Anat., 243, 81. Translated by M. Lev, and A. Vass. (1951). The Architecture of Normal and Malformed Hearts. Thomas, Springfield, Illinois.

Still, W. J. S. (1961). Endocardial fibroelastosis. Amer. Heart J., 61, 579. 